\title{
Study on effect of peptide-conjugated
} near-infrared fluorescent quantum dots on the clone formation, proliferation, apoptosis, and tumorigenicity ability of human buccal squamous cell carcinoma cell line BcaCD885

This article was published in the following Dove Press journal:

International Journal of Nanomedicine

12 June 2010

Number of times this article has been viewed

\author{
Deping Sun' \\ Kai Yang' \\ Gang Zheng² \\ Zhigang Li' \\ Yuan Cao' \\ 'Department of Oral and Maxillofacial \\ Surgery, the First Affiliated Hospital, \\ Chongqing Medical University, \\ Chongqing, China; ${ }^{2}$ Chongqing \\ Hospital of Traditional Chinese \\ Medicine, Chongqing, China
}

Correspondence: Kai Yang

Department of Oral and Maxillofacial Surgery, the First Affiliated Hospital,

Chongqing Medical University, Chongqing 400016, China

Tel +86023890I2569

Email cqfyyk@yahoo.com.cn

\begin{abstract}
Quantum dots (QDs) have shown great development potential in noninvasive imaging and monitoring of cancer cells in vivo because of their unique optical properties. However, the key issue of whether or not QDs-labeled cancer cells affect the proliferation, apoptosis and in vivo tumorigenicity ability has not been reported. The primary issue is if the results obtained from the noninvasive visualization of QDs-labeled tumors are scientific. Here, we applied peptide-linked near-conjugated fluorescent QDs to label human buccal squamous cell carcinoma cell line (BcaCD885). We performed in vivo tumorigenicity ability assays, tumorigenic cells proliferation, and apoptotic capability assays detected by flow cytometry and plate clone formation experiment, and found that peptide-linked near-conjugated fluorescent QDs labeling did not affect the growth, proliferation, apoptosis, and tumorigenicity ability of those cancer cells. Our study provides scientific foundation to support the application of near-infrared fluorescent QDs in noninvasive imaging and monitoring of cancer cells in vivo.
\end{abstract}

Keywords: quantum dots, near-infrared fluorescence, oral cancer, proliferation, apoptosis, tumorigenicity

\section{Introduction}

The noninvasive, real-time, and long-time imaging and tracking cancerous cells in vivo are of considerable interest in investigation of tumor occurrence, advances, early diagnosis, and treatment. In comparison with conventional organic and fluorescent protein probes, Quantum dots (QDs) have unique optical properties, such as high photoluminescence quantum yield, high intense fluorescence, excellent photostability, and high resistance to photobleaching and photodegradation. ${ }^{1-4}$ Especially, the recently developed QDs with an infrared emission wavelength between 700 and $900 \mathrm{~nm}$ has a powerful ability to penetrate human tissues and at the same time it can avoid the interference of tissue autofluorescence $(400-600 \mathrm{~nm})$, which is particularly suitable for noninvasive medical imaging. ${ }^{5-7}$ Currently, QDs have been used in noninvasive imaging of tumor cells, targeting imaging of tumor neovasculature, ${ }^{8-12}$ and detection of sentinel lymph nodes in live subjects through labeling tumor cells with QD, ${ }^{13,14}$ which demonstrate that QDs have satisfactory imaging capability in vivo. The unique optical properties of QDs make them appealing as in vivo fluorophores in investigation of tumor occurrence, advances, early diagnosis, and treatment. Recent work indicates that 
bioconjugated QDs are nontoxic to cells and have no effect on cells growth and differentiation in vitro. ${ }^{8,15}$ Some studies used QDs labeled cancer cells for the noninvasive imaging of cell growth and distribution in live subject, ${ }^{8-14}$ which provides an important basis for the investigation of tumor occurrence, advances, early diagnosis, and treatment. However, the key issue of whether or not QDs-labeled tumor cells affect the proliferation, apoptosis, and in vivo tumorigenicity ability has not been reported. The key issue that needs to be resolved is if the results obtained from the noninvasive visualization of QDs-labeled tumors are scientific and if the results reflect the actual tumor cell growth and invasion in vivo.

Ninety percent of malignant tumor in the oral and maxillofacial regions is squamous cell carcinoma. Buccal squamous cell carcinoma is one of the most common oral squamous cell carcinomas, with only $50 \%$ to $60 \%$ survival rate at five years ${ }^{16,17}$ and thus investigation on this tumor is of high significance. Recent studies have shown that membrane-penetrating peptide-conjugated QDs can label the cells effectively and rapidly. ${ }^{18-21}$ In this study, we used peptideconjugated near-infrared fluorescent QD (Qtracker ${ }^{\mathrm{TM}}$ QD800) with a maximal emission of $800 \mathrm{~nm}$ to label human buccal squamous cell carcinoma cell line (BcaCD885) through endocytosis. We then observed proliferation, apoptosis, and tumorigenicity ability of the QD800-labeled BcaCD885 cells in vivo. These results provided a theoretical basis to reveal if the visualized tumor cells labeled by peptide-conjugated near-infrared fluorescent QDs reflected the actual cancerous cells growth and distribution in vivo.

\section{Materials and methods \\ Materials}

The human buccal squamous cell carcinoma cell line BcaCD885 was provided by West China College of Stomatology, Sichuan University (Sichuan, China). Qtracker ${ }^{\mathrm{TM}} 800$ Cell Labeling Kit (Invitrogen, Carlsbad, CA, USA) uses a custom peptide to deliver QDs into the cytoplasm of live cells without cell-type specificity. Laser scanning confocal microscope was purchased from Leica (Tcs-sp5; Leica, Wetzlar, Germany). Flow cytometry machine (FACSVantage; BD, Franklin Lakes, NJ, USA) Low-speed refrigerated centrifuge (Z233MK-2) was from HERMLE, (Hosheim, Germany).

\section{Experimental animals}

Five female SPF level BALB/c nu/nu substrain nude mice, 5-6 weeks old and 19-20 g of weights, were purchased from the Experimental Animal Center of Chongqing Medical University. They were kept under the conditions of constant temperature and humidity, and sterile bedding, food, and water. They were kept under room temperature.

All experimental procedures were approved by the Laboratory Animal Management Committee of Experimental Animal Research Institute.

\section{Labeling BcaCD885 cells with QDs}

Labeling BcaCD885 cells with QD800 was performed according to the manufacturer's instructions. Briefly, trypsindigested BcaCD885 cells were transferred into EP tube with $1 \times 10^{6}$ cells and then $0.2 \mathrm{~mL}$ of QD800 labeling solution $(10 \mathrm{nM})$ was added. After mixing, the cells were co-cultured with QD800 for $1 \mathrm{~h}$ and centrifuged $(1,000 \times \mathrm{g})$ for $5 \mathrm{~min}$ at $4{ }^{\circ} \mathrm{C}$. The supernatant medium was discarded and the cell pellets were washed with PBS for 2 times to remove the uninternalized QDs. The QD800-labeled BcaCD885 cells (BcaCD885/QD800) were cultured continuously for $6 \mathrm{~h}$. And then the labeled cells were dispersed into suspension and the labeling efficiency was detected with flow cytometry. Laser-scanning confocal microscope was used to observe the distribution of QD within BcaCD885 cells. All the experiments were repeated 3 times and the average of the labeling rate was calculated accordingly.

\section{Plate clone formation assay}

Cell suspension $\left(5 \times 10^{6}\right.$ cells $\left./ \mathrm{mL}\right)$ of BcaCD885/QD800 used for the following experiments immediately was prepared according to the procedure described above. Suspensions of BcaCD885/QD800 and BcaCD885 were seeded into two $60 \mathrm{~mm}$ Petri dishes with $2 \times 10^{2}$ cells in each dish. The cells were dispersed evenly by slightly shaking the Petri dishes and then were incubated at $37^{\circ} \mathrm{C}$ with $5 \%$ of $\mathrm{CO}_{2}$ for $21 \mathrm{~d}$ until the visible clones appeared. The medium was discarded and the cells were carefully washed with PBS twice. After being fixed with methanol for $15 \mathrm{~min}$, the cells were stained with Giemsa's solution for 15 min before washing with tap water and air-drying. The clones with more than 50 cells were counted with an ordinary optical microscope and the clone formation rate was calculated with the following formula: Plate clone formation efficiency $=$ (number of clones/number of cells inoculated) $\times 100 \%$. All the experiments were repeated 3 times and the average values were reported.

\section{Tumorigenicity experiment}

After labeling, $0.1 \mathrm{~mL}$ of $\mathrm{BcaCD} 885 / \mathrm{QD} 800$ and BcaCD885 cells $\left(2 \times 10^{6}\right.$ cells $\left./ \mathrm{mL}\right)$ was immediately inoculated subcutaneously on the left and right backs of 5 nude mice. Tumorigenicity was monitored $21 \mathrm{~d}$ after inoculation, 
all mice sacrificed by neck-breaking and the tumors were taken out and weighed. The tumor's maximal long diameter $(a)$ and minimal short diameter $(b)$ were measured, and the volume of tumor was calculated by the equation of $V=0.5 \times a \times b^{2}$. Ten tumors were saved for the following detection of proliferation and apoptosis.

\section{Detection of proliferation and apoptotic capabilities of tumorigenic cells in vivo}

Tumor cells from those 10 fresh tumor tissues (BcaCD885/ QD800 and BcaCD885 5 specimens each) were suspended, and their proliferation and apoptosis were analyzed by flow cytometry. Brief description of the experimental procedure is as follows: each sample was cleaned by removing the surrounding necrotic tissues, washed 3 times with D-Hanks solution, treated with penicillin $\left(5 \times 10^{5} \mathrm{U} / \mathrm{L}\right)$ and streptomycin $(100 \mathrm{mg} / \mathrm{L})$ for $20 \mathrm{~min}$. Then each tumor was cut into $1 \mathrm{~mm}^{3}$ pieces, which were subsequently treated with digestion solution $(20 \mathrm{mg} / 10 \mathrm{~mL}$ of collagenase, $10 \mathrm{mg} / 10 \mathrm{~mL}$ of DNase, and $0.002 \mathrm{mg} / 10 \mathrm{~mL}$ of Hyaluronidase) for $40 \mathrm{~min}$ and filtered with 200-mesh tantalum net. The filtered solutions were centrifuged at $1000 \mathrm{r} / \mathrm{min}$ for $5 \mathrm{~min}$ and the pellets were washed 2 times with PBS and then resuspended in RPMI 1640 medium to make 10 cell suspension solutions for flow cytometry analyses.

Detection of tumorigenic cell proliferation with flow cytometry: all cell concentrations were adjusted to $1 \times 10^{6} / \mathrm{mL}$ and $1 \mathrm{~mL}$ of cell suspension solution was centrifuged $\left(1000 \mathrm{r} / \mathrm{min}, 4^{\circ} \mathrm{C}\right)$ for $5 \mathrm{~min}$. The pelleted tumor cells were fixed in $70 \%$ ethanol at $-20^{\circ} \mathrm{C}$ and then kept at $4^{\circ} \mathrm{C}$ overnight. The cells were spin down by centrifuging at $1000 \mathrm{r} / \mathrm{min}$ at $4^{\circ} \mathrm{C}$ for $5 \mathrm{~min}$, followed by 2 times of washing with $\mathrm{PBS}$ and $30 \mathrm{~min}$ staining with PI solution at $4{ }^{\circ} \mathrm{C}$ in dark. The following equation was used to calculate the proliferation index of tumor cell $(P I)$ : PI $=\left(S+G_{2} / M\right) /\left(G_{0} /\right.$ $\left.G_{1}+S+G_{2} / M\right) \times 100 \%$.
Detection of tumorigenic cell apoptosis with flow cytometry: all cell concentrations were adjusted to $1 \times 10^{6} / \mathrm{mL}$ and $1 \mathrm{~mL}$ of cell suspension solution was centrifuged (1000 r/min, $4^{\circ} \mathrm{C}$ ) for $5 \mathrm{~min}$. The pelleted tumor cells were washed 2 times with $4^{\circ} \mathrm{C}$ PBS, stained in $200 \mu \mathrm{L}$ of Annexin V staining solution at room temperature for $15 \mathrm{~min}$ then in $1 \mathrm{~mL}$ of PI staining solution for $5 \mathrm{~min}$ before flow cytometry analysis. The following equation was used to calculate the apoptosis index of tumor cell $(A I): A I=$ (number of apoptotic cells/total number of measured cells) $\times 100 \%$.

All the experiments were repeated for 3 times and the average values were reported.

\section{Statistical evaluations}

A Student's $t$-test was applied to analyze the data measured. All values are presented as means $\pm S D$. $P<0.05$ was considered statistically significant.

\section{Results}

\section{Labeling of BcaCD885 cells with QDs}

The labeling rate of BcaCD885 cells after $6 \mathrm{~h}$ was $(94.37 \pm 2.38 \%)$, as detected by flow cytometry. The average fluorescence intensity was $233.81 \pm 7.44$. After $6 \mathrm{~h}$, a large amount of QD800 was distributed in the cytoplasm, as detected by a laser confocal microscope (Figure 1).

\section{Effect of QDs on the BcaCD885 cell proliferation and apoptosis}

The average proliferation indexes of BcaCD885/QD800 and BcaCD885 cells were $(51.38 \pm 2.75 \%)$ and $(52.06 \pm 2.47 \%)$, respectively, which are not significantly different from each other $(P>0.05)$, and their average apoptosis indexes were $(10.22 \pm 0.81 \%)$ and $(9.53 \pm 0.74 \%)$, respectively, which are also not significantly different from each other $(P>0.05)$. These results indicate that QD800 labeling does not change the proliferation and apoptosis of BcaCD885 cells.
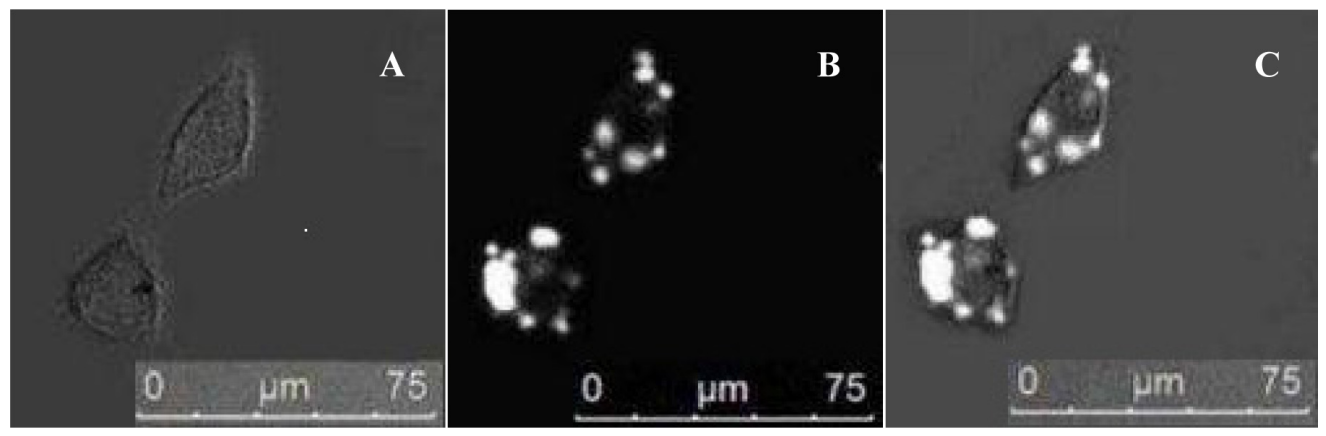

Figure I Fluorescent images of cells labeled with QD800 after 6 h. Bright-field (A). QD800 fluorescence image (B). Overlay image (C). 


\section{Effect of QDs on the BcaCD885 cell clone formation}

The clone formation efficiency BcaCD885/QD800 and BcaCD885 cells were $(64.7 \pm 5.4 \%)$ and $(66.2 \pm 3.1 \%)$, respectively, after $21 \mathrm{~d}$ of culture (Figure 2). Statistical analysis showed that there was no significant difference between the clonal formation rate of QDs-labeled cells and that of unlabeled cells, indicating that labeling of BcaCD885 cells with QD800 does not affect the clone forming ability.

\section{Effect of QDs on the BcaCD885 cell tumorigenicity in vivo}

Obvious tumorigenicity was observed in both BcaCD885/ QD800 group and BcaCD885 group 21 days after the subcutaneous inoculation. The average weights of tumors of BcaCD885/QD800 group and BcaCD885 group were $1.46 \pm 0.19 \mathrm{~g}$ and $1.52 \pm 0.21 \mathrm{~g}$, respectively, which are not significantly different from each other $(P>0.05)$. The average sizes of tumors were $2.83 \pm 0.74 \mathrm{~cm}^{3}$ and $2.95 \pm 0.81 \mathrm{~cm}^{3}$ for BcaCD885/QD800 group and BcaCD885 group, respectively, which are also not significant different from each other $(P>0.05)$. These results indicate that QD800 labeling does not change BcaCD885 cells tumorigenicity capacities in vivo (Figure 3 ).

\section{Effect of QDs on the BcaCD885 tumorigenic cells proliferation and apoptosis in vivo}

Twenty one days after tumorigenesis, the average proliferation indexes of BcaCD885/QD800 and BcaCD885 tumorigenic cells were $(49.57 \pm 2.06 \%)$ and $(50.68 \pm 2.24 \%)$, respectively, which are not significantly different from each other $(P>0.05)$, and their average apoptosis indexes were $(12.63 \pm 0.82 \%)$ and $(11.79 \pm 0.75 \%)$, respectively, which are also not significantly different from each other $(P>0.05)$.

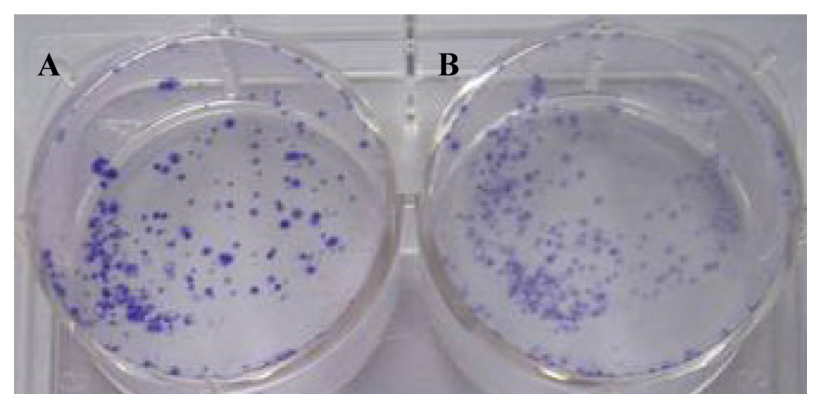

Figure 2 The clone formation efficiency of BcaCD885 cell treated or untreated with QD800 after 21 d of culture. Panel A indicated the unlabeled BcaCD885 cells and panel B indicated BcaCD885 labeled with QD800.

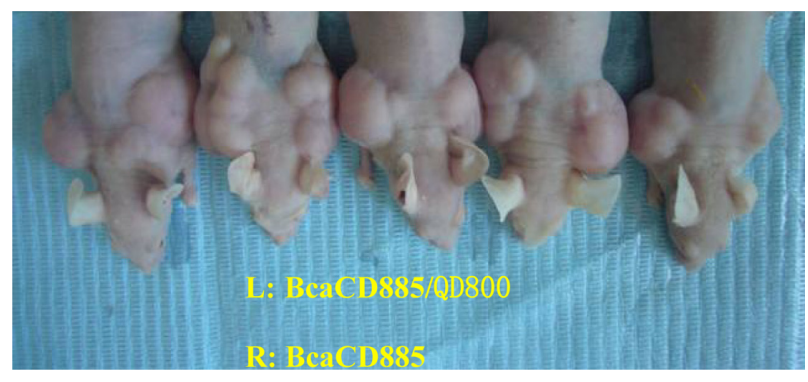

Figure $3 \mathrm{BcaCD} 885 / \mathrm{QD} 800$ and $\mathrm{BcaCD} 885$ cells tumorigenicity in vivo was monitored for $21 \mathrm{~d}$ after cells inoculation. The left backs $(L)$ of nude mice are $\mathrm{BcaCD} 885 / \mathrm{QD} 800$ group and the rights (R) are BcaCD885 group.

These results indicate that QD800 labeling does not change the proliferation and apoptosis capabilities of BcaCD885 tumorigenic cells.

\section{Discussion}

In comparison with conventional organic (eg, rhodamine, FITC, Cy3, and Cy5) and fluorescent protein probes, QDs developed due to multidisciplinary cross-cutting development and have unique optical properties, such as high photoluminescence quantum yield, high intense fluorescence, excellent photostability, and high resistance to photobleaching and photodegradation. ${ }^{1-4}$ The luminescence feature of QDs displays strict size effect: all kinds of spectra from UV to infrared wavelength or from blue to red wavelength can be obtained by changing the size of QDs. ${ }^{8}$ Therefore, live cell labeled with QDs makes it possible for long-term or simultaneous multicolor observation of multiple cell interactions. Currently, QDs have been used in noninvasive imaging of cancerous cells to reveal the cells growth and distribution in vivo. ${ }^{8-14}$ However, the issue of whether or not QDs affect the proliferation, apoptosis and tumorigenicity ability of tumor cells has not been reported. The key issue is precisely if the results obtained from the noninvasive visualization of QDs-labeled tumors are scientific to reflect the growth, proliferation, apoptosis, and tumorigenicity ability in vivo. Our study used peptide-conjugated maximum emission wavelength $800 \mathrm{~nm}$ near-infrared fluorescent quantum dots for labeling BcaCD885 cancer cells, these experiments proved that quantum dots can label BcaCD885 cells through entering quickly the cells, and the labeling rate of BcaCD885 cells after $6 \mathrm{~h}$ was 94.37\%. QD800 labeling of BcaCD885 cancer cells does not affect their proliferation, apoptosis, and tumorigenicity ability, and offered a scientific basis for in vivo the noninvasive in situ imaging of cell growth and distribution using near-infrared fluorescent quantum dots. 


\section{Conclusion}

Peptide-linked near-conjugated fluorescent QDs labeling showed no effects on the growth, proliferation, apoptosis, and tumorigenicity ability of those cancer cells. Our study provides scientific foundation to support the application of peptide-linked near-conjugated fluorescent QDs in noninvasive imaging and monitoring of cancer cells in vivo.

\section{Acknowledgments}

The study was supported by the National Natural Science Foundation of China (30872925).

\section{Disclosures}

The authors report no conflicts or competing financial interests in this work.

\section{References}

1. Medintz IL, Uyeda HT, Goldman ER, Mattoussi H. Quantum dot bioconjugates for imaging, labelling and sensing. Nat Mater. 2005:4:435-446.

2. Chan WC, Nie S. Quantum dot bioconjugates for ultrasensitive nonisotopic detection. Science. 1998;281:2016-2018.

3. Dahan M, Levi S, Luccardini C, Rostaing P, Riveau B, Triller A. Diffusion dynamics of glycine receptors revealed by single-quantum dot tracking. Science. 2003;302:442-445.

4. Hasegawa U, Nomura SM, Kaul SC, Hirano T, Akiyoshi K. Nanogelquantum dot hybrid nanoparticles for live cell imaging. Biochem Biophys Res Commun. 2005;331:917-921.

5. Gao X, Cui Y, Levenson RM, Chung LW, Nie S. In vivo cancer targeting and imaging with semiconductor quantum dots. Nat Biotechnol. 2004;22:969-976.

6. Morgan NY, English S, Chen W, Chernomordik V, Russo A, Smith PD, et al. Real time in vivo non-invasive optical imaging using near-infrared fluorescent quantum dots. Academic Radiolog. 2005;12:313-323.

7. Zimmer JP, Kim S-W, Ohnishi S, Tanaka E, Frangioni JV, Bawendi MG. Size series of small indium arsenide-zinc selenide core-shell nanocrystals and their application to in vivo imaging. $J$ Am Chem Soc. 2006;128:2526-2527.
8. Michalet X, Pinaud FF, Bentolila LA, Tsay JM, Doose S, Li JJ, et al Quantum dots for live cells, in vivo imaging, and diagnostics. Science. 2005;307:538-544.

9. Tada H, Higuchi H, Wanatabe TM, Ohuchi N. In vivo real-time tracking of single quantum dots conjugated with monoclonal anti-HER2 antibody in tumors of mice. Cancer Res. 2007;67:1138-1144.

10. Shi C, Zhu Y, Xie Z, Qian W, Hsieh CL, Nie S, et al. Visualizing human prostate cancer cells in mouse skeleton using bioconjugated near-infrared fluorescent quantum dots. Urology. 2009;74:446-451.

11. Voura EB, Jaiswal JK, Mattoussi H, Simon SM. Tracking metastatic tumor cell extravasation with quantum dot nanocrystalsand fluorescence emission-scanning microscopy. Nat Med. 2004;10:993-998.

12. Cai W, Shin DW, Chen K, Gheysens O, Cao Q, Wang SX, et al. Peptidelabeled near-infrared quantum dots for imaging tumor vasculature in living subjects. Nano Letters. 2006;6:669-676.

13. Frangioni JV, Kim SW, Ohnishi S, Kim S, Bawendi MG. Sentinel lymph node mapping with type ii quantum dots. Methods Mol Biol. 2007;374:147-159.

14. Soltesz EG, Kim S, Laurence RG, DeGrand AM, Parungo CP, Dor DM, et al. Intraoperative sentinel lymph node mapping of the lung using near-infrared fluorescent quantum dots. Ann Thorac Surg. 2005;79:269-277.

15. Jaiswal JK, Mattoussi H, Mauro JM, Simon SM. Long-term multiple color imaging of live cells using quantum dot bioconjugates. Nat Biotechnol. 2003;21:47-51.

16. Kademani D, Bell RB, Scbmidt BL, et al. Oral and maxillofacial surgeons treating oral cancer: a preliminary report from the American Association of Oral and Maxillofacial Surgeons Task Force on oral cancer. J Oral Maxillofac Surg. 2008;66:2151-2157.

17. Parkin DM, Bray F, Ferlay J, Pisani P. Global cancer statistics, 2002. CA Cancer J Clin. 2005;55:74-108.

18. Chen B, Liu Q, Zhang Y, Xu L, Fang X. Transmembrane delivery of the cell-penetrating peptide conjugated semiconductor quantum dots. Langmuir. 2008;24:11866-11871

19. Lin S, Xie X, Patel MR, Yang YH, Li Z, Cao F, et al. Quantum dot imaging for embryonic stem cells. BMC Biotechnol. 2007;7:67-77.

20. Xue FL, Chen JY, Guo J, Wang CC, Yang WL, Wang PN, et al. Enhancement of intracellular delivery of CdTe quantum dots (QDs) to living cells by Tat conjugation. J Fluoresc. 2007;17:149-154.

21. Santra S, Yang H, Stanley JT, Holloway PH, Moudgil BM, Walter G, et al. Rapid and effective labeling of brain tissue using TAT-conjugated CdS:Mn/ZnS quantum dots. Chem Commun. 2005;(25):3144-3146.
International Journal of Nanomedicine

\section{Publish your work in this journal}

The International Journal of Nanomedicine is an international, peerreviewed journal focusing on the application of nanotechnology in diagnostics, therapeutics, and drug delivery systems throughou the biomedical field. This journal is indexed on PubMed Central, MedLine, CAS, SciSearch ${ }^{\circledR}$, Current Contents ${ }^{\circledR} /$ Clinical Medicine,

\section{Dovepress}

Journal Citation Reports/Science Edition, EMBase, Scopus and the Elsevier Bibliographic databases. The manuscript management system is completely online and includes a very quick and fair peer-review system, which is all easy to use. Visit http://www.dovepress.com/ testimonials.php to read real quotes from published authors. 